\title{
Modelling of Vapour Condensation on Single Cylindrical Fin
}

\author{
Andrey Glushchuk, Patrick Queeckers, Carlo S. Iorio, Frank Dubois \\ Microgravity Research Centre, Université libre de Bruxelles \\ Avenue F. Roosevelt 50, 1050, Bruxelles, Belgium \\ aglushch@ulb.ac.be; pqueeck@ulb.ac.be; ciorio@ulb.ac.be; fdubois@ulb.ac.be
}

\section{Extended Abstract}

Many efforts can be found in the literature focusing on the investigation of condensation on the outside of horizontal finned tubes. Comprehensive overview can be found in the book of Rifert and Smirnov [1]. Three classes of prediction models exist based on various approaches: semi-empirical, numerical and surface segmentation. A third class is very adaptive to any fin shape that makes it very attractive. The modelling is based on the subdividing of the condensation surface into areas depending on the acting force: surface-tension pressure gradient vs gravity. Adamek and Webb [2] have fully formulated this method. It was successfully applied by other authors [3, 4] However, the calculation results are very sensitive to the segmentation algorithm. Such variety of different modeling ways and various calculation algorithms are the result of the lack of any reliable information about condensate flow on the fin.

Recently, Glushchuk et al. [5] presented the experimental investigation of vapour condensation on single cylindrical fin under various gravity conditions: $1 \mathrm{~g}_{0}, 1.8 \mathrm{~g}_{0}$ and $0.05 \mathrm{~g}_{0}$. A thickness of the condensate film was measured with micron accuracy. Curvature analysis of the condensate free surface revealed seven areas, each one being characterized by the main force acting on the liquid motion: gravitational vs surface-tension pressure gradient.

The goal of the present work is quantitative comparison of the segmentation method of the modelling and the experimental data reported in [5]. The model of vapour condensation on the cylindrical fin is developed basing on the approaches described in [4] and [2]. It provides the same number of the segments as in the experiments. Analysis of the calculation results reveals that the model shows smaller regions having strong effect of surface-tension pressure gradient. The most intensive vapour condensation takes place in these regions and the underrating of their sizes can affect negatively on the heat transfer prediction. As a result, the simulation gives under-predicted value of the overall heat transfer coefficient in comparison with measured one.

\section{References}

[1] V. G. Rifert and H. F. Smirnov, Condensation Heat Transfer Enhancement. Southampton, UK: WITpress, 2004.

[2] T. Adamek and R. L. Webb, "Prediction of film condensation on horizontal integral fin tubes," Int. J. Heat Mass Transfer, vol. 33, no. 8, pp. 1721-1735, 1990.

[3] M. Belghazi, A. Bontemps, C Marvillet, "Condensation heat transfer on enhanced surface tubes: experimental results and predictive theory," J. Heat Transfer, vol. 124, no. 4, pp. 754-761, 2002.

[4] R. Al-Badri, T. Gebauer, A. Leipertz, A. P. Fröba, "Element by element prediction model of condensation heat transfer on a horizontal integral finned tube," Int. J. Heat Mass Transfer, vol. 62, pp. 463-472, 2013.

[5] A. Glushchuk, Ch. Minetti, H. Machrafi, C, S. Iorio, "Experimental Investigation of Force Balance at Vapour Condensation on a Cylindrical Fin," Int. J. Heat Mass Transfer, vol. 108, pp. 2130-2142, 2017. 